\title{
ADJUVANT DERMATOLOGICAL THERAPY
}

\author{
Marcia de Matos Silva ${ }^{1}$, Patricia Karla de Souza ${ }^{2}$ \\ 1 Medcel, 2 Hospital Israelita Albert Einstein
}

Hematopoietic stem cell transplantation (HSCT) is associated with several skin manifestations including acute and chronic graft-versus-host disease (GVHD), disease relapse, opportunistic infections, and drug reactions, which can overlap with each other. The assertive diagnosis must be carried out before establishing a treatment plan ${ }^{[1]}$.

Acute GVHD (aGVHD) is a common complication in the early period post HSCT and the skin is often the first and most commonly affected organ. Symptoms begin ${ }^{[1-3]}$ weeks after HSCT and appear as maculopapular lesions, sometimes painful and/or pruritic, initially on the side of the neck, face, palms, plants, and ears, with the possibility of progression to erythroderma and bullous lesions similar to Steven Johnson's syndrome/NET ${ }^{[2,3]}$. The role of skin biopsy in diagnosis is still controversial ${ }^{[4,5]}$.

Chronic GVHD (cGVHD) is the most important late complication of HSCT. The skin is the organ most commonly involved and occurs in approximately $75 \%$ of patients ${ }^{[6]}$. The $\mathrm{NIH}^{[7]}$ consensus in 2014 suggested clinical manifestations for the diagnosis of cutaneous CGVHD: poikiloderma, lichen planus, and scleroderma alterations (morphea, lichen sclerosus, mobile, and non-mobile scleroderma). Other non-diagnostic findings include depigmentation, vitili- go, alopecia, and erythematopapular lesions with desquamation. Rarer clinical presentations include pityriasis rosea like, psoriasiform changes, and follicular keratosis ${ }^{[8]}$. Cutaneous manifestations of CGVHD are associated with itching and pain, reduced joint mobility, and increased risk of wound infections 9 . The immunomodulation resulting from prolonged therapy base on corticosteroids and a large number of second-line steroid-sparing therapies remains the focus of treatment for CGVHD.

Patient support is the basis for the treatment of cutaneous GVHD regarding the prevention and proper handling of dermatological changes and their symptoms, such as control of itching and pain; prevention of changes in joint mobility; topical treatment of erosions, ulcerations, and consequent superinfection.

Dermatological support includes direct skin therapy (DST), with the use of topical agents with anti-inflammatory and immunosuppressive action, and direct measures, with educational, psychosocial, and preventive actions, to control the symptoms and/or complications resulting from GVHD and of the drugs used to treat it. Unfortunately, responses to immunomodulation are often partial and patients continue to experience relapses of the disease and symptoms that impair quality of life. (Figure 1)

\section{FIGURE 1}

\section{PREVENTION MEASURES}

Photoprotection: anti-UVA and anti-UVB blockers ( $\geq$ SPF30)

Avoid sun exposure (especially between 10:00 and 16:00)

Protection with clothes

Avoid photosensitizing agents

\section{TREATMENT}

\section{- Intact skin}

Symptomatic treatment with emollient and antipruritic agents

Topical corticosteroids 
Phototherapy (PUVA, UVA1, UVB, UVB-NB)

Topical calcineurin inhibitors (pimecrolimus and tacrolimus)

\section{- Manifestations of sclerosis affecting the joint}

Deep muscle massage/fascia

Assessment of muscle strength at each visit

Guidance on physical and occupational therapy

Stretching exercises

Isokinetic, isometric, isotonic exercises

Surgical release

\section{- Erosions and ulcerations}

Oral and topical antimicrobials

Debridement and occlusive dressings on wounds

Edema control

\section{PEDIATRIC CONSIDERATIONS}

Systemic adverse effects of topical steroids can often occur in children due to the large surface area to be treated

Although low-potency topical steroids (1 to $2.5 \%$ hydrocortisone) are safe, medium and high potency steroids can be used in limited areas for a short time ( $<3-4$ weeks)

Topical steroids under occlusion are not recommended

The use of potent steroids in children $<1$ year is not recommended

The treatment of aGVHD grade I (mild) should consist of the optimization of prophylactic regimens, for example, with adjustment of cyclosporine or tacrolimus doses to achieve therapeutic serum levels. The use of corticosteroids and topical immunomodulators and systemic antihistamines helps in the control of pruritus and skin lesions. There is no indication of systemic immunosuppression.

The manifestations of mild GVHD (skin and mouth) can be treated with topical immunosuppression, avoiding systemic immunosuppressive $(\mathrm{SI})^{[10]}$ therapy. Clinical control of the disease aims to reduce morbidity and mortality with supportive measures such as DST that can improve cutaneous symptoms and quality of life of patients. Also, the optimized use of DST can reduce the amount of systemic immunosuppression required1, a fundamental factor in patients at high risk of relapse, so as not to interfere with the graft-versus-tumor effect ${ }^{[11]}$.

In moderate to severe GVHD, DST can be useful as an adjunct to increase the local response and facilitate the reduction of IS and toxicity. In the absence of poor prognostic factors, such as thrombocytopenia $(<100000 / \mu \mathrm{L})$, topical agents can be used as the primary treatment of cutaneous GVHD without the need for ISI (Figure 2). ${ }^{[9]}$ 
FIGURE 2 - Algorithm for the diagnosis and therapeutic orientation of cutaneous GVHD ${ }^{9}$

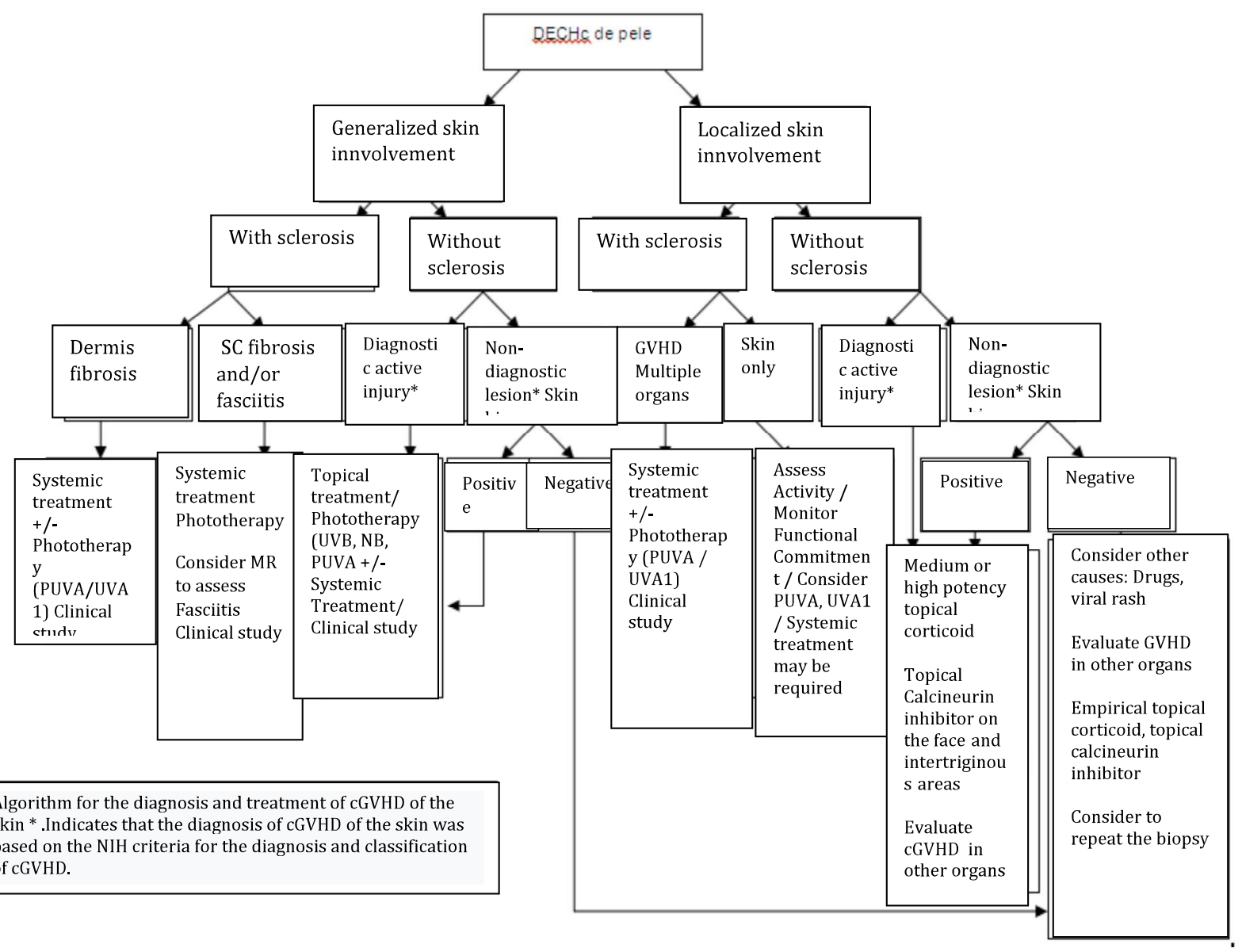




\section{REVENTIVE MEASURES FOR THE DEVELOPMENT AND EXACERBATION OF GVHD}

Ultraviolet (UV) radiation can cause exacerbation of cutaneous GVHD ${ }^{12}$. Photoprotection includes avoiding sun exposure, using chemical and physical photoprotectors that protect against UVA and UVB radiation (titanium dioxide, Mexoryl SX, or avobenzone), and wearing clothes with fabric that allows photoprotection.

\section{AVOIDING PHOTOSENSITIZING AGENTS}

Several prescribed medications are associated with drug phototoxicity skin rashes, which appear as lesions similar to severe sunburn and/or itching. The list of these medications is extensive, but voriconazole deserves special attention because of its frequent use and its association with phototoxic reactions and increased risk of cutaneous squamous cell carcinoma ${ }^{[13,14]}$.

\section{LOCAL THERAPIES AND CARE TO KEEP THE SKIN BARRIER INTACT}

On intact skin, lubrication with emollients reduces itching and maintains the integrity of the skin barrier, which is essential for innate immunity. Formulations based on 3-10\% urea are also effective, but care must be taken as they can be irritating when applied to inflamed skin in children and elderly patients.

\section{DIRECT SKIN THERAPY (DST)}

DST should be maintained as long as symptoms are present

\section{- TOPICAL STEROIDS (LEVEL OF EVIDENCE 1B, LEVEL OF RECOMMENDATION A)}

This is the first-line treatment for GVHD and mild to moderate cutaneous GVHD. Steroids have effects in reducing inflammatory epidermal cells, in responses to dendritic cells, in the synthesis of pro-inflammatory factors and collagen production. The degree of potency of topical corticosteroids is prescribed according to the affected site, vehicle, anatomical region, and depth of the lesion (epidermis - dermis - subcutaneous). (Figure 3). Thus, high potency such as clobetasol propionate and fluocinolone acetonide is prescribed for small areas and for a short time in lesions located on the body, palms and soles, and low and medium potency for face and more extensive and long-term areas, such as triamcinolone, desonide and hydrocortisone ${ }^{[15]}$. The scalp is the exception to the rule, where high-power corticosteroids can be used in vehicles based on solutions or oils.

For epidermal changes in GVHD such as ichthyosiform, lichenoid, and papules with desquamation, vehicles in the form of ointments may be used.

For scleroderma forms, high potency corticosteroids class 1 (for example clobetasol propionate) or class 2 (fluocinonide) should be indicated as first-line therapy.

For localized skin changes, steroids can be occlusive applied to increase effectiveness (products containing steroids in adhesive plastics or simply covering the cream with plastic).

For large areas, we should give preference to vehicles in the form of an emulsion or creamy lotion for ease of use.

The adverse effects of topical corticosteroids include skin atrophy, vascular dilation, acneiform rash, and hypopigmentation.

FIGURE 3 - Use of topical corticosteroids in cGVHD

\begin{tabular}{|c|c|c|c|}
\hline Corticoid potency & $\begin{array}{c}\text { High power } \\
\text { Ex. clobetasol propionate } 0.05 \% / \\
\text { Betamethasone Dipropionate } 0.05 \%\end{array}$ & $\begin{array}{c}\text { Moderate Power } \\
\text { Ex-mometasone furoate } 0.1 \% / \\
\text { Betamethasone valerate } 0.05 \% / \\
\text { fluticasone propionate } 0.05 \%\end{array}$ & $\begin{array}{c}\text { Low power } \\
\text { Ex: hydrocortisone }\end{array}$ \\
\hline Face & It should be avoided & $\begin{array}{c}2 x \text { day } \\
6-12 \text { months }\end{array}$ & $\begin{array}{l}2 \mathrm{x} \text { day } \\
\text { Prolonged use }\end{array}$ \\
\hline Body & $\begin{array}{c}2 \times \text { day } \\
\text { 4-12 weeks }\end{array}$ & & \\
\hline Palms and soles & $\begin{array}{l}2 \times \text { day } \\
\text { It can be used under occlusion to } \\
\text { increase the response. Prolonged } \\
\text { use may occur }\end{array}$ & & \\
\hline
\end{tabular}


- TOPICAL CALCINEURIN INHIBITORS (LEVEL OF EVIDENCE 2B, LEVEL OF RECOMMENDATION C)

Topical tacrolimus is widely used as a corticosteroid-sparing agent for atopic dermatitis. It acts by reducing the expression of cytokine in the skin, and it is effective for GVHD with mild and moderate cutaneous and oral involvement ${ }^{[15-17]}$. It can be used as a first-line treatment alone or in combination with topical steroids. In contrast to corticosteroids, tacrolimus does not affect collagen synthesis and can be used in areas of skin with signs of steroid atrophy and the appearance of stretch marks ${ }^{[3]}$.

\section{Oral antihistamines}

Pruritus in GVHD can have several origins such as dry skin, skin lesions, or the only symptom of disease activity. The $2^{\text {nd }}$ generation oral antihistamines (less hepatic metabolism), such as fexofenadine, epinastine, and bilastine, and the $1^{\text {st }}$ generation for more intense cases such as hydroxyzine are indicated to reduce itching. For refractory symptoms, the use of gabapentin or low dose thalidomide $(100 \mathrm{mg})$ may be associated.

\section{- ULTRAVIOLET RADIATION THERAPY (LEVEL OF EVIDENCE 2B, LEVEL OF RECOMMENDATION C)}

The experience with the use of ultraviolet radiation for the treatment of other inflammatory diseases stimulated the use of phototherapy with ultraviolet radiation $A$ associated with psoralen-PUVA method and phototherapy with narrow-band ultraviolet $B$ (UVBNB) to treat GVHD refractory to systemic corticotherapy ${ }^{[18-22]}$. The mechanism of action is related to the reduction of inflammation and cutaneous sclerosis, mediated by depletion of antigen-presenting cells in the skin and reduction of interactions with donor T cells. Phototherapy also increases the production of vitamin $D$, which appears to increase regulatory $T$ cells ( $T$ regs), involved in the pathology of GVHD 23.

PUVA is generally well tolerated with a high skin response rate and mild adverse effects. There is no evidence of the effectiveness of PUVA for the involvement of internal organs, but it should be considered in patients with CGVHD in whom additional systemic immunosuppression increases the risk of infection or interferes with the graft-versus-tumor response ${ }^{[19]}$. Feldreich et al. ${ }^{[24]}$ evaluated the response to PUVA treatment in 33 patients with aGVHD affecting the skin and other organs in a retrospective study, with a global response (complete and partial) of $64 \%$ and survival in 6 months of $64 \%$ and questioned a possible systemic effect of PUVA in other affected organs besides the skin.

PUVA is reserved for the treatment of dermal lesions (cGVHD mobile and non-mobile sclerosis), while UVBNB is indicated for vitiligo, lichen planus like, follicular keratosis, children, low skin phototypes (fair skin), and localized morphea. Reports on the use of UVBNB in scleroderma have been increasing. ${ }^{[25]}$

In all phototherapy modalities, long-term carcinogenesis and photoaging should be considered. However, the literature review involving 11 studies with approximately 3400 participants suggests that UVBNB phototherapy remains the safest modality 26. The current trend is to opt for UVBNB phototherapy due to the lower risk of photocarcinogenesis and phototoxic reactions to drugs ${ }^{[27,28]}$.

\section{OPICAL THERAPY AND CARE FOR NON-INTACT SKIN}

Skin erosions and ulcerations in cGVHD are complicated by poor nutrition, impaired skin barrier function, chronic disease, and concomitant immunosuppressive therapy. Primary and secondary infections in the lesions can be evaluated by microbiological cultures for bacteria, viruses, mycobacteria, and fungi. The differential diagnosis of non-infectious skin lesions includes vasculitis, recurrent malignancy, GVHD, hypersensitivity, drug reactions, eczema, and primary skin cancer. In the naked area, topical antimicrobials (mupirocin and fusidic acid), products containing $1 \%$ silver sulfadiazine, and alginate hydrogel, protective films based on petrolatum can be used to improve healing.

Recalcitrant wounds should be treated together with the plastic surgeon and/or dermatologist, and those with slow healing can be treated with products based on hyaluronic acid, collagen, fibroblasts, and keratinocytes. Hyperbaric oxygen therapy has been used in wounds with little oxygenation. Compressive therapy may be indicated to facilitate drainage in wounds with surrounding edema.

The appropriate use of dermatological support therapies helps to manage skin changes after HSCT and quality of life. Multidisciplinary follow-up plays an important role in the effectiveness of treating cutaneous changes in GVHD. 


\section{REFERENCES}

1. Kim Y, Lee G, Kwong B Y, et al. Evidence-based, Skin-directed Treatments for Cutaneous Chronic Graft-versus-host Disease. Cureus v. 11, n.12, p. 6462, 2019.

2. Nassereddine S, Rafei H, Elbahesh E, Tabbara I. Acute Graft Versus Host Disease: A Comprehensive Review. Anticancer Res. v. 37, n.4, p. 15471555, 2017,

3. Kavand S, Lehman JS, Hashmi S, Gibson LE, ElAzhary RA. Cutaneous manifestations of graftversus-host disease: role of the dermatologist. Int J Dermatol. v.56, n. 2, p. 131-140, 2017.

4. Kuykendall TD and Smoller BR: Lack of specificity in skin biopsy specimens to assess for acute graft-versus-host disease in initial 3 weeks after bone-marrow transplantation. J Am Acad Dermatol v.49, n.6, p. 1081-1085, 2003.

5. Haimes $H$, Morley KW, Song $H$, Okhovat JP, Schmidt B, Huang JT. Impact of skin biopsy on the management of acute graft-versus-host disease in a pediatric population. Pediatr Dermatol. v. 36, n.4, p. 455-459, 2019.

6. Lee SJ, Flowers MED: Recognizing and managing chronic graft-versus-host disease. Hematology Am Soc Hematol Educ Program . p. 134-41, 2008.

7. Jagasia MH, Greinix HT, Arora M, et al:: National Institutes of Health Consensus Development Project on Criteria for Clinical Trials in Chronic Graft-versus-Host Disease: I. The 2014 Diagnosis and Staging Working Group report. Biol Blood Marrow Transplant. v. 21, p. 389401, 2015.

8.Cornejo CM, Kim EJ, Rosenbach M, Micheletti RG: Atypical manifestations of graft-versushost disease. J Am Acad Dermatol. v. 72, p. 690-95, 2015.

9. Carpenter PA, Kitko CL, Elad S, et al:: National Institutes of Health Consensus Development Project on Criteria for Clinical Trials in Chronic Graft-versus-Host Disease: V. The 2014 Ancillary Therapy and Supportive Care Working Group Report. Biol Blood Marrow Transplant. v.21, p. 1167-87, 2015.

10. Filipovich AH, Weisdorf D, Pavletic $S$, et al. National Institutes of Health consensus development project on criteria for clinical trials in chronic graft-versus-host disease: I. Diagnosis and Staging Working Group report. Biol Blood Marrow Transplant. v.11, p. 945-956, 2005.
11. Lee SJ, Klein JP, Barrett AJ, et al. Severity of chronic graftversus-host disease: association with treatment-related mortality and relapse. Blood. v.100, p. 406-414, 2002.

12. Kitajima T, Imamura S. Graft-versus-host reaction enhanced by ultraviolet radiation. Arch Dermatol Res. v.285, n.8, p. 499-501, 1993.

13.Patel AR,Turner ML,Baird K, etal.Voriconazole-induced phototoxicity masquerading as chronic graft-versus-host disease of the skin in allogeneic hematopoietic cell transplant recipients. Biol Blood Marrow Transplant. v. 15, p, 370-6, 2009.

14. Epaulard O, Leccia MT, Blanche S, et al. Phototoxicity and photocarcinogenesis associated with voriconazole. Med Mal Infect. v. 41, n.12, p. 63945, 2011.

15. Wolff D, Gerbitz A, Ayuk F, et al. Consensus conference on clinical practice in chronic graft-versus-host disease (GVHD): first-line and topical treatment of chronic GVHD. Biol Blood Marrow Transplant v.16, p. 1611-1628, 2010.

16. Choi CJ, Nghiem P.Tacrolimus ointment in the treatment of chronic cutaneous graftvs-host disease: a case series of 18 patients. Arch Dermatol. v. 137, n.9, p. 1202-6, 2001.

17. Elad S, Or R, Resnick I, et al. Topical tacrolimus--a novel treatment alternative for cutaneous chronic graft-versus-host disease. Transpl Int. v.137, n.9, p. 665-70, 2003.

18. Vogelsang GB, Wolff D, Altomonte V,et al. Treatment of chronic graft-versus-host diseasewith ultraviolet irradiation and psoralen(PUVA). Bone Marrow Transplant. v. 17, p. 1061-1067, 1996.

19. Bouzas LF. 1996. Doença enxerto-contra-hospedeiro crônica em transplante de medula óssea:tratamento com psoraleno e ultravioleta $A$. Dissertação( Mestrado em Hematologia)-Faculdade de Medicina, Universidade Federal do Rio de Janeiro. Rio de Janeiro, 1996.

20. Bouzas, LFS ; Ferman, S ; Matta, JLR , et al. Treatment of chronic graft versus host disease with 8-methoxypsoralen and ultravioleta. Blood. v. 82, p. 420 AR, 1993.

21. Ballester-Sánchez,M.Á. Navarro-Mira, B. de Unamuno-Bustos, et al. The Role of Phototherapy in Cutaneous Chronic Graft-vs-Host Disease: A Retrospective Study and Review of the Literature Actas Dermosifiliogr. v. 106, n.8, p. 651-657, 2015. 
22. Garbutcheon-Singh KB,Fernández-Peñas $P$. Phototherapy for the treatment of cutaneous graft versus host disease. Australas J Dermatol. v. 56, n. 2, p. 93-9, 2015.

23. van der Aar AM, Sibiryak DS, Bakdash G, et al. Vitamin D3 targets epidermal and dermal dendritic cells for induction of distinct regulatory $T$ cells. J Allergy Clin Immunol v. 127, p. 7, 2011.

24. (Feldreich N, Ringden O, Emtestam L, Omazic B. Photochemotherapy of Cutaneous Graft-versusHost Disease May Reduce Concomitant Visceral Disease. Dermatology. v. 232, n. 4, p. 453-463, 2016.

25. Feldstein JV, Bolanos-Meade J, Anders VL, Abuay R.Narrowband ultraviolet B photother- apy for the treatment of steroid-refractory and steroid-dependent acute graft-versus host disease of the skin. J Am Acad Dermatol v.65, p. 733$8,2011$.

26. Lee E, Koo J, Berger T: UVB phototherapy and skin cancer risk: a review of the literature. Int J Dermatol. v. 44, p. 355-60, 2005.

27.Treister N, Li S, Lerman MA, et al. Narrow-band UVB phototherapy for management of oral chronic graft-versus-host disease. Photodermatol Photoimmunol Photomed. v. 31, n.2, p. 75-82, 2015.

28. Sokolova A, Lee A, D Smith S. The Safety and Efficacy of Narrow Band Ultraviolet B Treatment in Dermatology: A Review. Am J Clin Dermatol. 2015 Sep 14. Epub ahead of print 150. 